\title{
Competitive Proposals for Major Research Instrumentation Program of NSF: Tips and Facts
}

\section{R.S. Yassar,}

* Mechanical Engineering-Engineering Mechanic Department, Michigan Technological University, Houghton, MI 49931

National Science Foundation provides Major Research Instrumentation (MRI) awards to tens of applicants each year to support their instrumentation acquisition or development. The author has been among the recipients of MRI grants in the past and has served in the MRI panels. I would like to share my experience on how to write a competitive proposal to stand out among many proposals that this program receives. The focus of my talk will be on equipment acquisition. This program requires $30 \%$ cost share from the PIs and some tips will be given to accommodate cost share in your budget. 